\title{
Honokiol Inhibits Vascular Vessel Formation of Mouse Embryonic Stem Cell-Derived Endothelial Cells via the Suppression of PECAM and MAPK/mTOR Signaling Pathway
}

\author{
Gi Dae Kim ${ }^{1}$ Song Yi Bae ${ }^{1}$ Hyun-Joo Park ${ }^{1}$ Kihwan Bae ${ }^{2}$ Sang Kook Lee ${ }^{1}$ \\ ${ }^{1}$ College of Pharmacy, Seoul National University, Seoul, ${ }^{2}$ College of Pharmacy, Chungnam National \\ University, Daejon
}

\section{Key Words}

Honokiol • Anti-angiogenesis - PECAM • Differentiation • MAPK • mTOR • Mouse embryonic stem cells

\begin{abstract}
Embryonic stem cells, which are characterized by pluripotency and self-renewal, have recently been highlighted in drug discovery. In particular, the potential of ES cells to differentiate into specific-cell types make them an extremely useful tool in the evaluation of the biological activity of test compounds. Honokiol, a major neolignan derived from the bark of Magnolia obovata, has been shown an anti-tumor activity. However, the precise mechanism of action in the anti-tumor activity of honokiol is still poorly understood. Here, we evaluated the antiangiogenic activity of honokiol using mouse ES cell-derived embryoid bodies. mES-derived EBs were formed using hanging drop cultures and vascular formation was induced on gelatincoated plates in EGM-2 medium. The growth inhibition of honokiol was found to be more sensitive in the differentiated EB-derived endothelial cells compared to the undifferentiated EB-derived cells. Honokiol also inhibited the vascular formation of mES cells on 3-D collagen gel and decreased the expression of endothelial biomarkers VEGFR2 and PECAM in the differentiated EB-derived endothelial cells. In addition, honokiol suppressed the MAPK and mTOR signaling pathways in the EB-derived endothelial cells. Therefore, the anti-angiogenic activity of honokiol is associated in part with the suppression of PECAM and MAPK/mTOR pathways in EB-derived endothelial cells.
\end{abstract}

Copyright $\odot 2012$ S. Karger AG, Basel 


\section{Introduction}

Embryonic stem (ES) cells were first established from the inner cell mass of mouse blastocysts [1]. Mouse embryonic stem (mES) cells can be expanded continuously in culture with mitotic inactivated embryonic fibroblast cells, maintaining multi-lineage differentiation capability [1]. The differentiation of embryonic stem cells from embryo-like aggregates, embryoid bodies (EBs), could potentially result in the development of many cell types such as hematopoietic, neuronal, cardiomyocytes, muscle cells, epithelial and endothelial cell lineages [2]. ES cells have been shown to be a useful tool for the study of vasculogenesis and angiogenesis including angioblast differentiation, proliferation, migration, endothelial cellcell adhesion and vascular morphogenesis [3-5]. A diverse approach has evolved to induce differentiation of ES cells into endothelial cells. One promising approach was conducted using EBs for further differentiation from ES cells. EBs represents a good in vitro model not only for vasculogenesis (the formation of vessels from endothelial progenitors) but also for angiogenesis (the formation of new vessels from preexisting ones) in a 2-D or 3-D culture system $[6,7]$. Therefore, the ES/EB system allows for the study of both vasculogenesis and angiogenesis. This unique property confers superiority over all other in vitro angiogenesis models. In particular, EB-derived endothelial cells have been considered a useful tool to study endothelial cell biology and developmental processes. This process is characterized by the expression of endothelial cell-specific molecules during the formation of vascular structures in ES-derived EBs. The expression of a number of biomarkers, including VEGFR2 and PECAM, has been reported in vasculogenesis $[8,9]$.

Angiogenesis is the formation of new blood vessels from the pre-existing blood vasculature by the sprouting, splitting and remodeling of the vascular network. Angiogenesis is a complex process that results from an ordered set of events involving endothelial cell activation, growth, migration and capillary morphogenesis. VEGF is one of the most essential factors regulating angiogenesis. VEGF activity is mediated by the VEGF receptors (VEGFR)-1 (Flt-1, $180 \mathrm{kDa}$ ) and VEGFR-2 (KDR/Flk-1, $200 \mathrm{kDa}$ ), both of which are almost exclusively expressed in endothelial cells [10]. The binding of VEGF to VEGFRs and the subsequent ligand-induced dimerization of these receptors stimulate their intrinsic tyrosine kinase activity, which triggers key angiogenic responses in endothelial cells, including proliferation, migration, differentiation and protection from apoptosis. These effects are mediated via a number of different signaling cascades [11]. VEGF induces autophosphorylation of VEGFR2, followed by activation of downstream signaling pathways such as MAPK and mTOR stimulating angiogenesis. VEGF is also known to activate three MAPKs including ERK [12], SAPK/JNK [13], Akt [14], p38 MAPK [15] and mTOR [16, 17] in endothelial cells. mTOR is a serine/threonine protein kinase that exists as two functional protein complexes, mTORC1 and mTORC2 [18]. This kinase also regulates cell growth, cell cycle progression and angiogenesis by phosphorylating of eukaryotic initiation factor $4 \mathrm{E}$ binding protein 1 . Indeed, the activation of the MAPK/mTOR signaling pathway in endothelial cells promotes their survival when cultured in vitro [19] and in the tumor vasculature in vivo [20]. PECAM, a member of the immunoglobulin super-family, is expressed by endothelial cells and a subset of hematopoietic cells in the adult organism [21]. Additionally, undifferentiated ES cells have also been shown to express PECAM [22]. Thus, PECAM is a cell surface marker for endothelial cells and endothelial sprouting in vasculogenesis and angiogenesis [23].

Anti-angiogenic strategies have been proven to be a useful approach in patients with a high risk of developing cancer, cancer recurrence or the development of metastases. The identification of low-toxic anti-angiogenic or angio-preventive compounds derived from natural products is considered an achievable goal in the search for anti-cancer or cancer chemopreventive agents. In a previous study, we reported that mES might be an alternative model in which to evaluate the effect of 5-FU on vasculogenesis [24, 25]. In our continuous effort to identify anti-cancer agents, we established a mES in vitro screening system to evaluate the anti-angiogenic effects of natural product-derived compounds. Honokiol is a neolignan from the bark of Magnolia obovata Thunberg (Magnoliaceae) that has traditionally 
been used to enhance the function of the gastrointestinal tract in Asian countries. Honokiol was also found to be a potent scavenger of hydroxyl radicals [26, 27]. Recent studies have also reported various biological effects of neolignans including neuroprotection against oxidative stress [28-30], suppression of metastasis [14], anti-inflammatory activity [31, 32], anti-angiogenesis [33, 34] and anti-proliferation in a wide range of cancer cell types [3537]. Honokiol is an especially potent inhibitor of angiogenesis that attenuates endothelial cell proliferation and the growth of angiosarcomas [14]. However, the precise mechanism of action of the anti-angiogenic activity of honokiol is still poorly understood.

In the present study, we demonstrated that the anti-angiogenic activity of honokiol is associated with the suppression of PECAM expression and the down-regulation of MAPK/ mTOR pathways in mES-derived endothelial cells.

\section{Materials and Methods}

\section{Test compounds}

Honokiol (purity > 98\%, Fig. 2) isolated from the bark of Magnolia obovata was provided by Dr. K Bae [27]. The compound was dissolved in $100 \%$ DMSO.

\section{Cell culture}

Mouse $\mathrm{D}_{3}$ ES cells (ATCC Cat. No. CRL-1934, Rockville, MD, USA) were co-cultured with mitomycin $\mathrm{C}$ treated mouse embryonic fibroblasts in high glucose DMEM (Invitrogen, Carlsbad, CA, USA) containing $15 \%$ fetal bovine serum (Hyclone, Ogden, UT, USA), $1000 \mathrm{U} / \mathrm{ml}$ of LIF (Chemicon, Temecula, CA, USA), and basic ES medium components [ $50 \mathrm{U} / \mathrm{ml}$ of penicillin and $50 \mu \mathrm{g} / \mathrm{ml}$ streptomycin (Invitrogen, Carlsbad, CA, USA), $1 \%$ non-essential amino acids (Invitrogen, Carlsbad, CA, USA) and $0.1 \mathrm{mM} \beta$-mercaptoethanol (Invitrogen, Carlsbad, CA, USA)]. The hanging drop method (20 $\mu \mathrm{l}$ per drop; $1 \times 10^{5}$ cells $/ \mathrm{ml}$ ) was used to induce differentiation as described by Heuer and colleagues [38]. The EBs were formed by incubating hanging drop cultures for three days. The resulting EBs was transferred onto gelatin-coated chamber slides (Nunc, Denmark) or $60 \mathrm{~mm}$ dishes to allow for attachment. Endothelial cell differentiation was induced in EBs by switching culture conditions to medium containing EBM-2, 5\% FBS, growth factor cocktail, and ascorbic acid (EGM2-MV Bullet Kit; Lonza, Walkersville, MD, USA). Viable cells were directly observed under an inverted phase contrast light microscope (Olympus Optical Co. Ltd., Tokyo, Japan).

\section{ES cell characterization assay}

Alkaline phosphatase activity and SSEA-1 of cultured cells were analyzed according to manufacturer's instruction (Kit, Chemicon, Temecula, CA, USA).

\section{Growth inhibition assay}

The growth inhibition activity in cultured mES cells was determined by MTT assays with or without LIF as previously described [39]. Briefly, cells (0.3-1 x $10^{4}$ cells/ml) were seeded into a 96-well plate and grown in the presence of test compounds. At the early stage (differentiation day 1) or the late stage (differentiation day 10), the cells were exposed to various concentrations of compounds for $24 \mathrm{hrs}$. After incubation, MTT solution was added and incubated for an additional $4 \mathrm{hrs}$. The resulting formazan was dissolved with DMSO and the absorbance was detected at $570 \mathrm{~nm}$ with a VersaMax ELISA microplate reader (Molecular Devices, Sunnyvale, CA, USA). After treatment of honokiol for $24 \mathrm{hrs}$ at differentiation day 10, the effects of honokiol on cytotoxicity were tested using the CytoTox $96^{\circledR}$ Non-Radioactive Cytotoxicity Assay (Promega, Madison, WI, USA). The viability and cytotoxicity activity of honokiol were calculated as a percentage, relative to solvent-treated control. The $\mathrm{IC}_{50}$ values were calculated using a non-linear regression analysis of percent growth versus concentration.

\section{RNA isolation and reverse transcription-polymerase chain reaction (RT-PCR)}

Cells were sorted into tubes containing Trizol ${ }^{\circledR}$ (Invitrogen, Carlsbad, CA, USA) and total RNA was extracted according to the manufacturer's protocol. The isolated RNA was quantified using a NanoDrop spectrophotometer (NanoDrop Technologies, Inc., Wilmington, DE, USA). First-strand cDNA was synthesized 
Kim/Bae/Park/Bae/Lee: Honokiol Inhibits Angiogenesis via PECAM Suppression in mES Cells

Table 1. Sequences of oligonucleotide primers used for RT-PCR analysis

\begin{tabular}{|c|c|c|}
\hline Gene & Primer Sequences & Product size (bp) \\
\hline OCT4 & $\begin{array}{l}\text { F 5'-GTGCGATTGTCATCTCCAGG-3' } \\
\text { R 5'-GGGAGTCGGGAGGACTGATA-3' }\end{array}$ & 153 \\
\hline VEGFR2 & $\begin{array}{l}\text { F 5'-GTGGTCTTTCGGTGTGTTGC-3' } \\
\text { R 5'-ATAATGGAATTTGGGGTCGC-3' }\end{array}$ & 403 \\
\hline PECAM & $\begin{array}{l}\text { F 5'- CCATCATGGGAGGTGATGAA-3' } \\
\text { R 5'- GATACGCCATGCACCTTCAC-3' }\end{array}$ & 278 \\
\hline GAPDH & $\begin{array}{l}\text { F 5'- GGAGCCAAAAGGGTCATCAT-3' } \\
\text { R 5'- GTGATGGCATGGACTGTGGT-3' }\end{array}$ & 212 \\
\hline
\end{tabular}

from $2 \mu \mathrm{g}$ of total RNA using an oligo (dT) primer and a SuperScript First-Strand Synthesis System for RTPCR (Invitrogen, Carlsbad, CA, USA) according to the manufacturer's instructions. First-strand cDNAs were amplified in a final volume of $25 \mu \mathrm{l}$ containing $0.5 \mathrm{U}$ Taq DNA polymerase (TaKaRa Bio Inc., Otsu, Shiga, Japan) and 10 pmol of each target primer. PCR conditions were as follows: 5 min at $94^{\circ} \mathrm{C}, 30$ amplification cycles (denaturation at $94^{\circ} \mathrm{C}$ for $30 \mathrm{sec}$, annealing at $55-60^{\circ} \mathrm{C}$ for $30 \mathrm{sec}$, and extension at $72^{\circ} \mathrm{C}$ for $30 \mathrm{sec}$ ), followed by a final extension at $72^{\circ} \mathrm{C}$ for $5 \mathrm{~min}$. The amplified products were separated on $1.5 \%$ agarose gels. The gel was stained with SYBR ${ }^{\circledR}$ Gold staining solutions (Invitrogen, Carlsbad, CA, USA) and visualized under the UV transilluminator (GelDoc ${ }^{\mathrm{TM}} \mathrm{XR}$, BioRad Molecular Imager, USA). cDNA samples were adjusted to yield equal GAPDH amplifications. Sequences of the PCR primers are listed in Table 1.

\section{Western blot analysis}

Cells were treated with honokiol for $24 \mathrm{hrs}$. Harvested cells were lysed in protein extraction solution (Intron Biotechnology, Inc., Kyunggi, Korea) containing protease inhibitors and phosphatase inhibitors for $10 \mathrm{~min}$ at $4^{\circ} \mathrm{C}$. Protein concentration was measured by the Bradford assay. Equal amounts ( $40 \mu \mathrm{g}$ ) of protein samples were subjected to 6-15\% SDS-PAGE. Separated proteins were transferred to PVDF membranes (Millipore, Bedford, MA, USA). Membranes were incubated with primary antibodies diluted (1:2001:1000) in 5\% non-fat dry milk in TBST overnight at $4^{\circ} \mathrm{C}$. Membranes were washed three times with TBST and incubated with corresponding secondary antibodies. Protein bands were detected with an enhanced chemiluminescence detection kit (Intron Biotechnology, Inc., Kyunggi, Korea) and a LAS-1000 Imager (Fuji Film Corp., Tokyo, Japan). Anti-PECAM, anti-ERK, anti-phospho-ERK, anti-p38 $\alpha$, anti-phospho-p38, and secondary antibodies were from Santa Cruz Biotechnology (Santa Cruze Biotechnology, Santa Cruz, CA, USA). Anti-Akt, anti-phospho-Akt, anti-SAPK/JNK, anti-phospho-SAPK/JNK, anti-mTOR, anti-phosphomTOR anti-4EBP1, anti-phospho-4EBP1, PD98059, and LY294002 were purchased from Cell Signaling Biotechnology (Cell Signaling Biotechnology, Danvers, MA, USA). $\beta$-actin antibody was from Sigma (Sigma, St. Louis, MO, USA).

\section{Immunocytochemistry}

Cells were plated onto cover slips and induced endothelial-like cells with EGM-2 medium for 10 days. The endothelial like-cells incubated with honokiol for $24 \mathrm{hrs}$. After incubation, the cells were fixed with $4 \%$ paraformaldehyde and incubated overnight at $4^{\circ} \mathrm{C}$. The cells were blocked with blocking solution containing 1\% BSA/PBS for $30 \mathrm{~min}$, and then incubated with rat anti-mouse PECAM (1:200) (Santa Cruze Biotechnology, Santa Cruz, CA, USA) overnight at $4^{\circ} \mathrm{C}$. After washing, the cells were incubated with Alexa Fluor 594-labeled chicken anti-rat IgG (1:1000) (Invitrogen, Carlsbad, CA, USA). After staining, the cover slips were mounted with medium containing DAPI (Vector Laboratories, Burlingame, CA, USA). Confocal microscopy was performed on a Zeiss Model 710 (Carl Zeiss, Jena, Germany). 


\section{3-Dimensional type-I collagen sprouting angiogenesis model}

The three-dimensional tube formation and sprouting angiogenesis model were performed in typeI collagen [6, 7]. Briefly, EBs derived from mES were cultured in suspension containing EGM-2 medium for 7 days. The EBs were then plated in type-I collagen solution and incubated in EGM-2 medium at $37^{\circ} \mathrm{C}$. The vascular sprout was induced by incubation with test compounds for 4 days. Vascular sprout morphology was analyzed using a phase contrast microscope (Nikon, Eclipse TE 2000-U, Tokyo, Japan). For immunofluorescence staining, EBs were grown in type-I collagen and stained with Alexa Fluor 488 antimouse PECAM antibody ( $1 \mu \mathrm{g} / \mathrm{ml}$, Invitrogen) or Alexa Fluor 488 rat IgG2a antibody $(1 \mu \mathrm{g} / \mathrm{ml}$, Invitrogen) for $10 \mathrm{hrs}$ at $37^{\circ} \mathrm{C}$ and washed with EGM-2 medium containing $5 \%$ bovine serum and growth factors for 15 min 3 times at $37^{\circ} \mathrm{C}$. Immunostaining of PECAM was detected by a Zeiss Model 710 (Carl Zeiss, Jena, Germany) confocal microscope.

\section{Statistical analysis}

Results are expressed as mean \pm S.D. Statistical analysis was determined using ANOVA and Student's $t$-test for paired data. A P-value of $<0.05$ was considered statistically significant. Statistical calculations were performed using SPSS for Windows Version 10.0 (SPSS, Chicago, IL, USA).

\section{Results}

Induction of differentiation for endothelial-like cells from $m E S$ cells

We primarily employed EBs formed from mES cells to generate endothelial cells. EBs were formed by a hanging drop culture of mES cells and transferred to an adherent culture using gelatin-coated plates. The morphological changes of endothelial cells formed from mES-derived EBs were found to be dependent on the stage of differentiation (Fig. 1A). Especially, the morphological changes of mES-derived endothelial cells show the spreading from the center part of mEB (Fig. 1A-c) and the enhancing for proliferation and differentiation through cell-to-cell contact (marked an arrow) by migration (Fig. 1A-d). As shown in Fig. 1B, mES cells expressed high levels of alkaline phosphatase activity, and SSEA-1 recognizing specific cell surface antigens. RT-PCR analysis showed that the expression of endothelial biomarkers including VEGFR2 and PECAM was increased in EB-derived endothelial cells cultured for 11 days. These events were also highly correlated with decreased expression of OCT4, an undifferentiated or stemness biomarker, during the endothelial differentiation of cells derived from mES cells (Fig. 1C). Additionally, the expression of PECAM in EB-derived endothelial cells was also increased and capillary-like structures were observed on day 4 and day 11 by immunocytochemistry (Fig. 1D). These results suggest that the established mES-derived EBs were capable of differentiating into endothelial cells. The induction of differentiation was also confirmed by the expression of endothelial cell biomarkers at the mRNA and protein levels. The expression of PECAM was consistently increased depending on the endothelial differentiation stage.

\section{Inhibition of the EB-derived differentiated endothelial cell growth by honokiol}

To validate the usefulness of the mES-derived endothelial cells, the effects of honokiol on the growth of these cells were determined by the MTT assay. mES-derived endothelial cells at different stages of differentiation were treated with honokiol for 24 hrs. As shown in Fig. 3A, The growth inhibition in the early stage (differentiation day 1) and late stage (differentiation day 10) cells after $24 \mathrm{hrs}$ of incubation with honokiol was significantly different $(\mathrm{p}<0.05)$. The $\mathrm{IC}_{50}$ values were 43 and $32 \mu \mathrm{M}$, respectively (Fig. $\left.3 \mathrm{~A}\right)$. These data suggest that the differentiated endothelial cells derived from mES cells are more sensitive to honokiol-mediated inhibition of cell growth than undifferentiated mES-derived cells. To further determine the concentration ranges of honokiol without cytotoxicity in the differentiated endothelial-like cells, the cells were treated with honokiol $(0-100 \mu \mathrm{M})$ for $24 \mathrm{hrs}$ and analyzed the cytotoxicity using LDH leakage assays (Fig. 3B). Over $50 \mu \mathrm{M}$ honokiol 


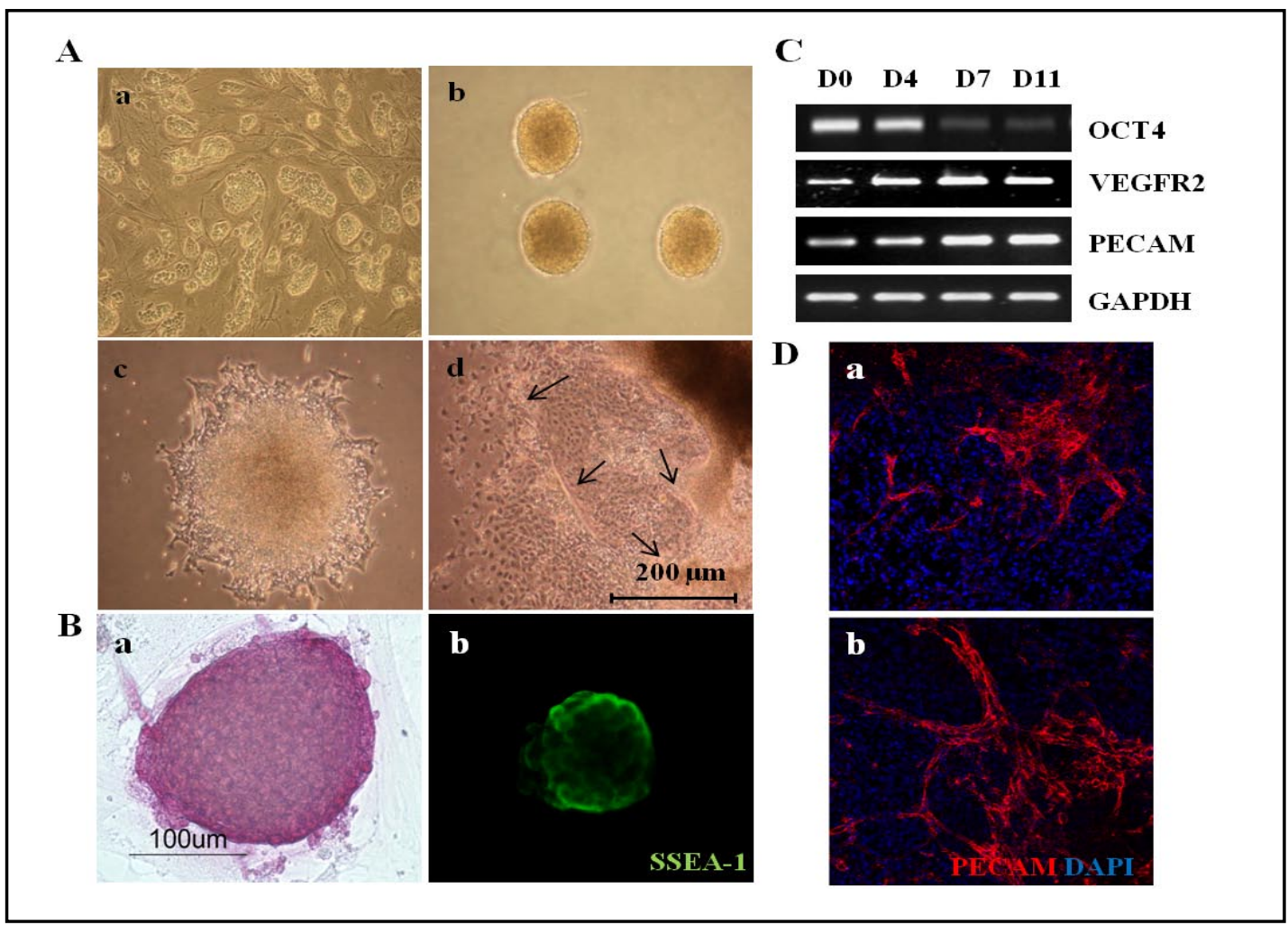

Fig. 1. Sequential morphological and endothelial marker expression of mES cells during the differentiation process. (A) mES cells on CF1 feeder cells (A-a), Day 3 embryoid body (EB) after hanging drop culture (A-b), Morphology of Day 4 (A-c) and Day 11 (A-d) differentiated EBs after attachment to a gelatin-coated culture plate. Magnification: $\mathrm{A} \times 40$. (B) $\mathrm{mES}$ cells cultured for 4 days in $10^{3}$ units $/ \mathrm{ml}$ recombinant mouse LIF on feeder layer of mouse embryonic fibroblasts were fixed and tested for alkaline phosphatase activity with a colorimetric assay (B-a). Immunofluorescent staining of mES cells, stained with anti-SSEA-1 antibody. Undifferentiated ES cells (cultured in presence of LIF) revealed positive immuno-staining for SSEA-1 (B-b). Magnification: B×200. (C, D) Analysis of the expression of endothelial cell-specific markers by RT-PCR and immunofluorescence in mES-derived embryoid bodies. Day 0 corresponds to mRNA from ES cells cultured in the presence of LIF. Days 4 through 11 indicate days of culture after LIF deprivation. GAPDH was served as an internal control (C). mES cells were differentiated into EBs, fixed on days 4 (D-a) and 11 (D-b) and stained with PECAM antibody. Magnification: D × 100 .

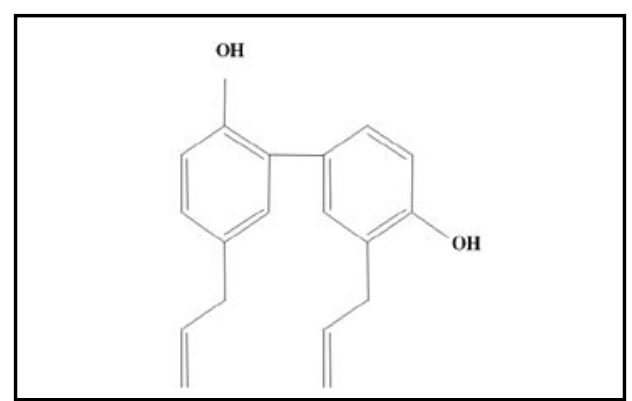

Fig. 2. Chemical structure of honokiol.

treatment showed a cytotoxic effect. Therefore, the further analysis of biological activities of honokiol was performed under $20 \mu \mathrm{M}$ in the differentiated endothelial-like cells.

Suppression of honokiol on the expression of VEGFR2 and PECAM

To determine whether honokiol-mediated the inhibition of endothelial cell growth was associated with the suppression of endothelial biomarker expressions, the EB-derived 


\section{Cellular Physiology Cell Physiol Biochem 2012;30:758-770

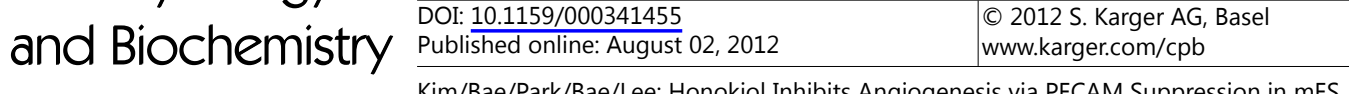 \\ Kim/Bae/Park/Bae/Lee: Honokiol Inhibits Angiogenesis via PECAM Suppression in mES Cells}

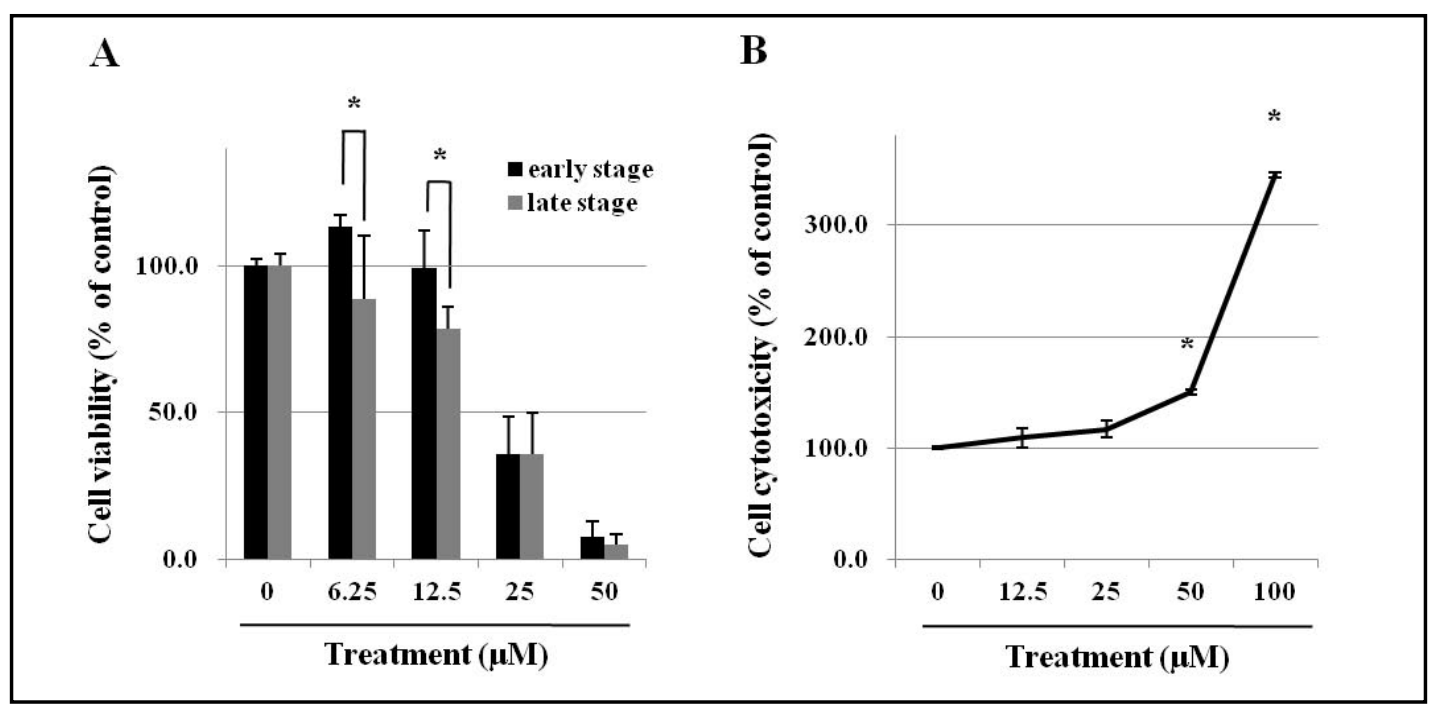

Fig. 3. Effects of honokiol on cell viability or cytotoxicity in mES cells as determined by MTT or LDH assays. (A) The respective concentrations of honokiol $(0-50 \mu \mathrm{M})$ required for a $50 \%$ reduction $\left(\mathrm{IC}_{50}\right)$ in the early stage (differentiation day 1) and late stage (differentiation day 10) cultures were assessed for $24 \mathrm{hrs}$. (B) LDH leakage was measured after $24 \mathrm{hrs}$ with the treatment of honokiol $(0-100 \mu \mathrm{M})$. Cell viability and cytotoxicity were expressed as a percentage of control cultured in the absence of honokiol, and reported as the mean \pm S.D. Results are representative of three separate experiments. ${ }^{*} P<0.05$ compared with/without differentiation.

endothelial cells (differentiation day 10) were treated with honokiol (0 - $20 \mu \mathrm{M})$ for $24 \mathrm{hrs}$. After treatment, the gene and protein expression of the endothelial specific biomarkers VEGFR2 and PECAM were analyzed. As shown in Fig. 4A, honokiol dose-dependently suppressed the expressions of mRNA of VEGFR2 and PECAM. The suppressive expression of VEGFR2 and PECAM protein was also found by honokiol treatment (Fig. 4B), indicating that honokiol suppressed the expression of VEGFR2 and PECAM in the mRNA and protein level.

The anti-angiogenic activity of honokiol was also assessed by measuring the expression of the endothelial biomarker PECAM in a 2-dimensional (2-D) culture. As shown in Fig. 4C-a, PECAM was easily detected by immunofluorescence in the EB-derived endothelial cells. However, the expression of PECAM was attenuated with honokiol treatment in a concentration-dependent manner (Fig. 4C-b, 4C-c).

Honokiol-mediated inhibition of sprouting angiogenesis in embryoid body derived from mES cells

Three-dimensional (3-D) collagen gel has previously been used to induce vascular tube formation. In this study, tube formation was induced by the incubation of mES-derived EBs in EGM-2 medium. The mES-derived EBs were cultured in suspension containing EGM-2 medium for 7 days, then plated in type-I collagen gel solution and finally incubated in EGM2 medium with test compounds for 4 days. As shown in Fig. 4D-a, the morphology of the vascular sprout in EB-derived endothelial cells was observed after 4 days of induction. When embryoid bodies were grown in the presence of honokiol $(5$, or $10 \mu \mathrm{M})$, vascular sprouting was completely blocked while control group greatly accelerated vascular tube sprouting and extensive network of cellular outgrowths (Fig. 4D-E).

In addition, the inhibition of vascular sprouting by honokiol in the EB-derived endothelial cells was also confirmed by the suppression of PECAM expression determined using the immunofluorescence staining (Fig. 4F). This result suggests that honokiol may inhibit vascular sprouting activity. These data suggest that honokiol have anti-angiogenic activity in EB-derived endothelial cells in 2-D and 3-D culture system. 
Cellular Physiology $\quad$ Cell Physiol Biochem 2012;30:758-770 and Biochemistry $\begin{aligned} & \text { Dor: 10.1159/000341455 } \\ & \text { Published online: August 02, } 2012\end{aligned}$

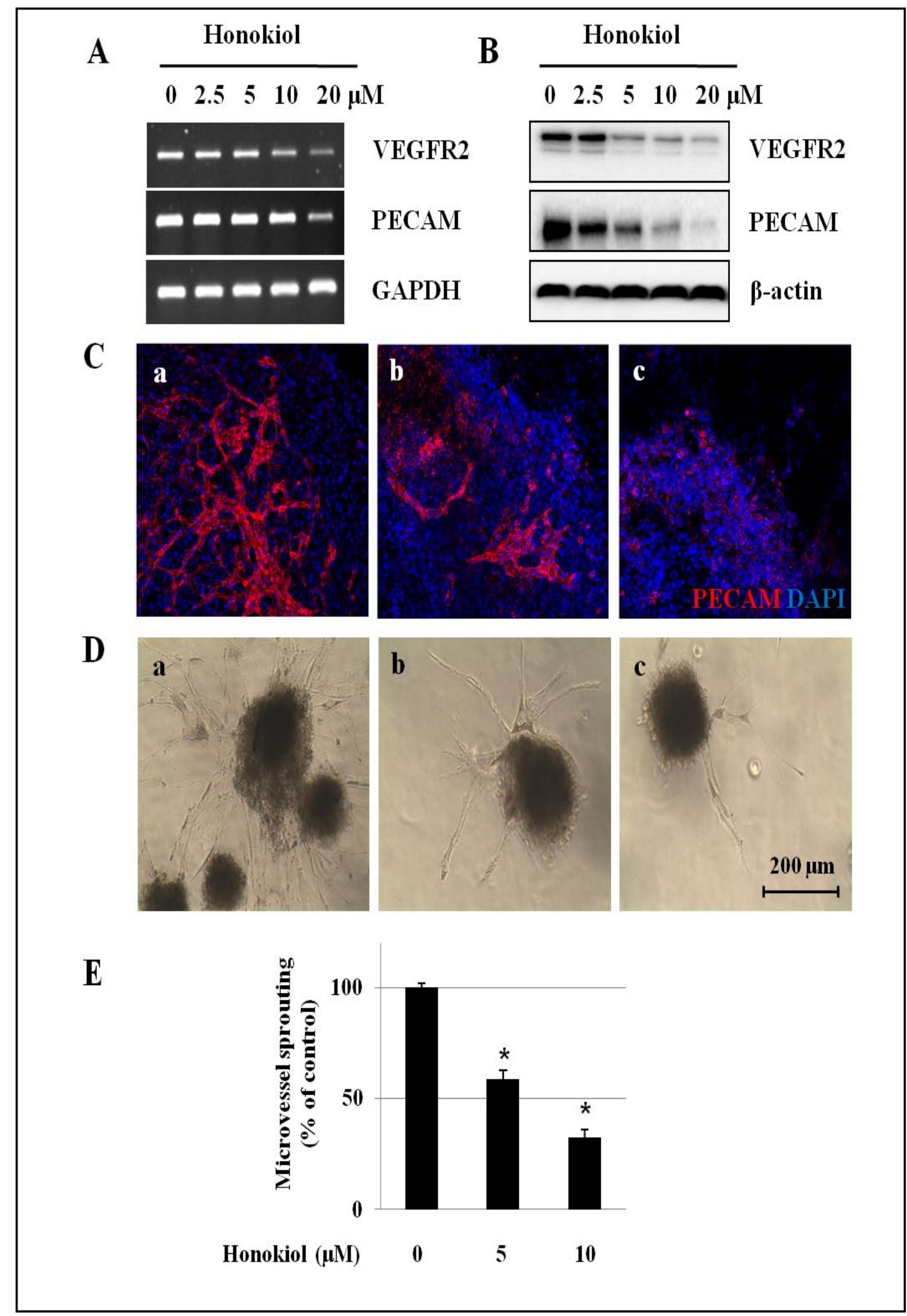

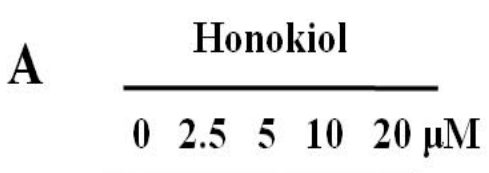

b 


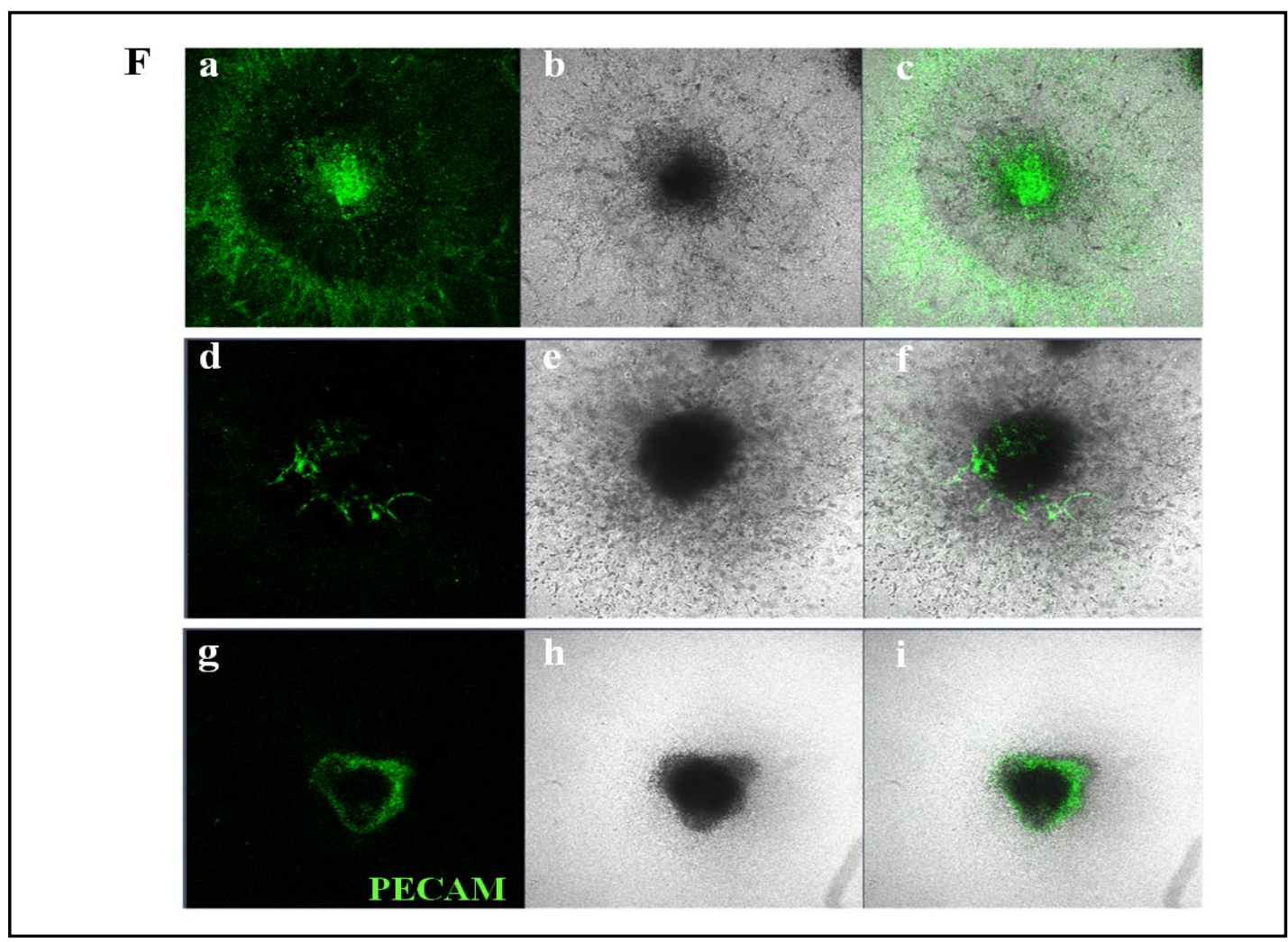

Fig. 4. Effect of honokiol on vascularization of endothelial cells derived from the EBs. The EBs were differentiated for 10 days and then treated with honokiol $(0-20 \mu \mathrm{M})$ for 24 hrs. (A) Expression of VEFGR2 and PECAM mRNA in the EB-derived endothelial cells was detected by RT-PCR analysis. GAPDH was used as an internal control. (B) Expression of VEFGR2 and PECAM protein levels in cell lysate from EB-derived endothelial cells after $24 \mathrm{hrs}$ incubation with honokiol $(0-20 \mu \mathrm{M})$ were measured by Western blot analysis. $\beta$-actin was used as an internal control. (C) The EB-derived endothelial cells were exposed to honokiol $(0,5$, and $10 \mu \mathrm{M})$ at differentiation day 10 for $24 \mathrm{hrs}$. The EB-derived endothelial cells were stained with an antibody directed against an endothelial cell biomarker PECAM using immunofluorescence. Cell nuclei were stained with DAPI. Control (C-a), $5 \mu \mathrm{M}$ of honokiol (C-b), and $10 \mu \mathrm{M}$ of honokiol (C-c). Magnification $\times$ 100. (D) EBs derived from mES were cultured in suspension containing EGM-2 medium for 7 days. The EBs embedded in collagen gel were treated with honokiol for 4 days. Endothelial sprouting activity of EBderived endothelial cells was altered with honokiol $(0,5,10 \mu \mathrm{M})$ treatment. The morphology of endothelial sprouting of EB-derived endothelial cells in control (D-a) and honokiol treatment (D-b: $5 \mu \mathrm{M}$ and D-c: 10 $\mu \mathrm{M}$ ) after 4 days of secondary culture in collagen gel. (E) The quantification of sprouting number by honokiol treatment compared to control in Fig. 4D. Statistical analysis was performed with Student's $t$-test. ${ }^{*} P<0.05$ vs. vehicle control. Magnification $\times 40$. (F) Confocal analysis of PECAM expression on sprouting EB in 3D culture. Sprouting EB was stained with antibodies to PECAM (a, d, g), imaged by phase contrast (b, e, h), and merged with two images (c, f, i). Magnification $\times 100$.

\section{Suppression of MAPK and mTOR signaling by honokiol in EB-derived endothelial cells}

We next determined whether the suppression of endothelial biomarkers by honokiol is mediated by signaling molecules associated with cell proliferation and angiogenesis. Activation of MAP kinases including p38 $\alpha$, Akt, ERK1/2, and SAPK/JNK were down-regulated by the treatment of honokiol $(0-20 \mu \mathrm{M})$ in the EB-derived endothelial cells. In addition, the activation of $\mathrm{mTOR}$ and its downstream effector including 4EBP1 were also suppressed by honokiol (Fig. 5A). To further confirm the association of ERK and PI3K signaling pathway, the effects of MEK inhibitor PD98059 [40] and PI3K inhibitor LY294002 [41] were evaluated. As shown in Fig. 5B, honokiol exhibits the similar suppression pattern with ERK and/or PI3K inhibitor in the EB-derived endothelial cells. In addition, the co-treatment of ERK or PI3K inhibitor with honokiol also enhanced the suppression of the activation of ERK and PI3K 


\section{Cellular Physiology Cell Physiol Biochem 2012;30:758-770

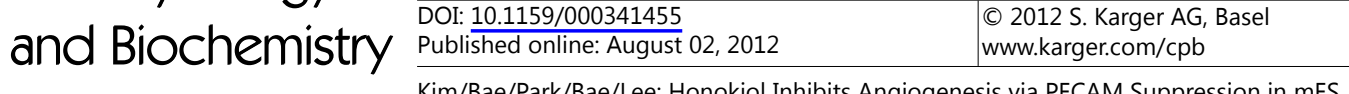

\section{A}
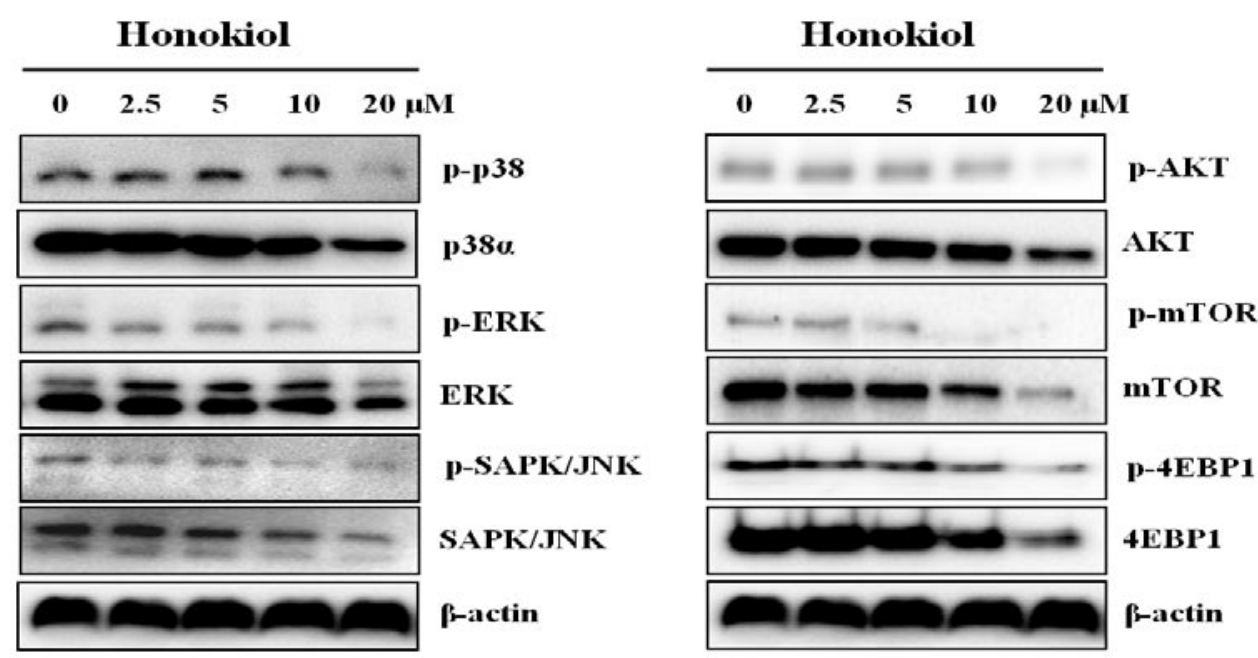

B
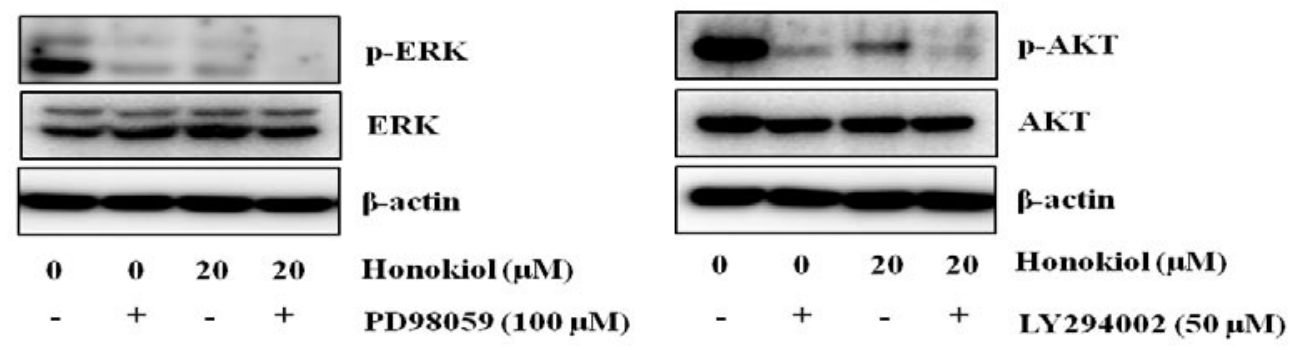

Fig. 5. Effect of honokiol on MAPK/mTOR pathways in the EB-derived endothelial cells. (A) Protein extract $(40 \mu \mathrm{g})$ was resolved by 6-15\% SDS-PAGE, and total and phosphorylated p38 MAPK, ERK1/2, SAPK/JNK, AKT, mTOR and 4EBP1 were detected by Western blotting. (B) Effect of co-treatment of MEK inhibitor PD98059 and/or PI3K inhibitor LY294002 with honokiol on the expression of p-ERK and p-AKT. $\beta$-actin was used as an internal control.

signalings. These data suggest that the suppression of VEGFR2 and PECAM by honokiol is in part mediated by the down-regulation of MAPK/mTOR signalings in the endothelial cell proliferation and angiogenesis.

\section{Discussion}

We established methods to differentiate mouse embryonic stem cells into endotheliallike cells and vessel formations. Further studies were performed to determine the utility of the model in evaluating the anti-angiogenic activity and its mechanism of action of honokiol in EB-derived endothelial cells. To our knowledge, this is the first report to evaluate the anti-angiogenic activity and its mechanism of action of honokiol using embryonic stem cells. Because anti-angiogenic compounds are potential cancer chemotherapeutic agents, we evaluated the anti-angiogenic activity of honokiol in established assay systems using the EBderived endothelial cells. Although neolignans including honokiol have been reported to have potent anti-proliferative and anti-angiogenic activity [14,42,43], the precise mechanism of action of the anti-angiogenic effects of honokiol in in vitro and in vivo systems are not well 
understood. To establish mES-derived endothelial cells, we formed EBs with the hanging drop method using mES cells [38]. The EBs were differentiated in a gelatin-coated plate and the differentiation stage was monitored by measuring expression of the endothelial cell biomarkers VEGFR2 and PECAM.

In the present study with mES-derived EBs, we found that the expression of VEGFR2 was dependent on the stage of endothelial cell differentiation; thus, VEGFR2 expression might reflect a commitment to differentiation to an endothelial lineage. PECAM was also expressed in undifferentiated mES cells and the expression level was increased by differentiation into endothelial cells. These results are consistent with previous studies that examined expression of PECAM in endothelial cells [44]. We next validated the usefulness of the EBderived endothelial cells in determining the anti-angiogenic potential of honokiol in several assay systems. Honokiol suppressed the expression of VEGFR2 and PECAM in the EB-derived endothelial cells. This result suggests that the anti-angiogenic activity of honokiol might be associated with the suppression of VEFGR2 and PECAM expression in endothelial cells. In angiogenesis, MAP kinases are activated by various stimuli including VEGF in endothelial cells and regulate multiple critical steps by phosphorylating different downstream substrates such as mTOR [45]. MAPK/mTOR signaling is one of the critical molecular events during growth, survival and migration in VEGF-induced angiogenesis of vascular endothelial cells $[46,47]$. To determine whether the anti-angiogenic activity of honokiol is associated with the modulation of MAPK/mTOR signaling pathways the expression of MAPK/mTOR signaling molecules was determined in the EB-derived endothelial cells. Honokiol suppressed the phosphorylation of ERK1/2, SAPK/JNK, Akt, mTOR and 4EBP1 in the EB-derived endothelial cells. This might be one plausible mechanism of action for the anti-angiogenic or anti-proliferative activity of honokiol in endothelial cells. Because angiogenesis involves endothelial cell migration and proliferation within a collagen rich extracellular matrix, we established an in vitro angiogenic sprouting model system using mES-derived three-dimensional EB models [48]. When mESderived EBs matured in a type-I collagen gel they formed capillary-like structures as observed by morphological changes (3-D culture) and expression of PECAM (2-D culture). In this angiogenic sprouting model treatment with honokiol blocked the formation of the primitive vascular network structures in 17-day-old mES-derived EBs. This result also confirmed that honokiol inhibited angiogenic sprouting of endothelial cells.

In summary, the present study shows that mES-derived EBs might provide useful models to study the early differentiation and development of blood vessels and angiogenesis, and also to use as a tool in the screening of pharmacologically interesting compounds. Additionally, the mES-derived EB model system was used to demonstrate that the anti-angiogenic activity mediated by honokiol involved the suppression of the endothelial biomarkers VEGFR2 and PECAM, and the modulation of MAPK/mTOR signaling pathways.

\section{Acknowledgements}

This work was supported by the National Research Foundation of Korea (NRF) grant funded by the Korean Government (MEST) (MRC No. 2011-30635) and (NRF-2010-355E00069).

\section{References}

-1 Evans MJ, Kaufman MH: Establishment in culture of pluripotential stem cells from mouse embryos. Nature 1981;291:154-156.

2 Rathjen PD, Lake J, Whyatt LM, Bettess MD, Rathjen J: Properties and uses of embryonic stem cells: Prospects for application to human biology and gene therapy. Reprod Fertil Dev 1998;10:31-47. 


\section{Cellular Physiology $\quad$ Cell Physiol Biochem 2012;30:758-770

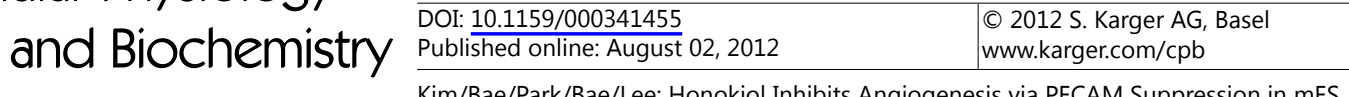

3 Doetschman TC, Eistetter H, Katz M, Schmidt W, Kemler R: The in vitro development of blastocyst-derived embryonic stem cell lines: formation of visceral yolk sac, blood islands and myocardium. J Embryol Exp Morphol 1985;87:27-45.

4 Risau W, Sariola H, Zerwes HG, Sasse J, Ekblom P, Kemler R, Doetschman T: Vasculogenesis and angiogenesis in embryonic-stem-cell-derived embryoid bodies. Development 1988;102:471-478. Li X, Claesson-Welsh L: Embryonic stem cell models in vascular biology. J Thromb Haemost 2009;1:53-56. Jakobsson L, Kreuger J, Holmborn K, Lundin L, Eriksson I, Kjellén L, Claesson-Welsh L: Heparan sulfate in trans potentiates VEGFR-mediated angiogenesis. Dev Cell 2006;10:625-634.

7 Kawamura H, Li X, Goishi K, van Meeteren LA, Jakobsson L, Cébe-Suarez S, Shimizu A, Edholm D, BallmerHofer K, Kjellén L, Klagsbrun M, Claesson-Welsh L: Neuropilin-1 in regulation of VEGF-induced activation of p38MAPK and endothelial cell organization. Blood 2008;112:3638-3649.

-8 Yamaguchi TP, Dumont DJ, Conlon RA, Breitman ML, Rossant J: flk-1, an flt-related receptor tyrosine kinase is an early marker for endothelial cell precursors. Development 1993;118:489-498.

-9 Redick SD, Bautch VL: Developmental platelet endothelial cell adhesion molecule expression suggests multiple roles for a vascular adhesion molecule. Am J Pathol 1999;154:1137-1147.

-10 Yancopoulos GD, Davis S, Gale NW, Rudge JS, Wiegand SJ, Holash J: Vascular-specific growth factors and blood vessel formation. Nature 2000;407:242-248.

11 Sakurai Y, Ohgimoto K, Kataoka Y, Yoshida N, Shibuya M: Essential role of Flk-1 (VEGF receptor 2) tyrosine residue 1173 in vasculogenesis in mice. Natl Acad Sci USA 2005;102:1076-1081.

-12 Kanno S, Oda N, Abe M, Terai Y, Ito M, Shitara K, Tabayashi K, Shibuya M, Sato Y: Roles of two VEGF receptors, Flt- 1 and KDR, in the signal transduction of VEGF effects in human vascular endothelial cells. Oncogene 2000;19:2138-2146.

13 Meadows KN, Bryant P, Vincent PA, Pumiglia KM: Activated Ras induces a proangiogenic phenotype in primary endothelial cells. Oncogene 2004;23:192-200.

-14 Bai X, Cerimele F, Ushio-Fukai M, Waqas M, Campbell PM, Govindarajan B, Der CJ, Battle T, Frank DA, Ye K, Murad E, Dubiel W, Soff G, Arbiser JL: Honokiol, a small molecular weight natural product, inhibits angiogenesis in vitro and tumor growth in vivo. J Biol Chem 2003;278:35501-35507.

15 Wu G, Luo J, Rana JS, Laham R, Sellke FW, Li J: Involvement of COX-2 in VEGF-induced angiogenesis via P38 and JNK pathways in vascular endothelial cells. Cardiovasc Res 2006;69:512-519.

16 Foster KG, Acosta-Jaquez HA, Romeo Y, Ekim B, Soliman GA, Carriere A, Roux PP, Ballif BA, Fingar DC: Regulation of mTOR complex 1 (mTORC1) by raptor Ser863 and multisite phosphorylation. J Biol Chem 2010;285:80-94.

17 Hwang M, Perez CA, Moretti L, Lu B: The mTOR signaling network: insights from its role during embryonic development. Curr Med Chem 2008;15:1192-1208.

18 Sparks CA, Guertin DA: Targeting mTOR: prospects for mTOR complex 2 inhibitors in cancer therapy. Oncogene 2010;29:3733-3744.

-19 Olsson AK, Dimberg A, Kreuger J, Claesson-Welsh L: VEGF receptor signalling-in control of vascular function. Nat Rev Mol Cell Biol 2006;5:359-371.

-20 Benjamin LE, Keshet E: Conditional switching of vascular endothelial growth factor (VEGF) expression in tumors: induction of endothelial cell shedding and regression of hemangioblastoma-like vessels by VEGF withdrawal. Proc Natl Acad Sci USA 1997;94:8761-8766.

-21 Delisser HM, Baldwin HS, Albelda SM: Platelet Endothelial Cell Adhesion Molecule 1 (PECAM-1/CD31): A Multifunctional Vascular Cell Adhesion Molecule. Trends Cardiovasc Med 1997;7:203-210.

-22 Vittet D, Prandini MH, Berthier R, Schweitzer A, Martin-Sisteron H, Uzan G, Dejana E: Embryonic stem cells differentiate in vitro to endothelial cells through successive maturation steps. Blood 1996;88:3424-3431.

23 Newman PJ: The biology of PECAM-1. J Clin Invest 1997;99:3-8.

-24 Kim GD, Kim GJ, Seok JH, Chung HM, Chee KM, Rhee GS: Differentiation of endothelial cells derived from mouse embryoid bodies: a possible in vitro vasculogenesis model. Toxicol Lett 2008;180:166-173.

25 Kim GD, Rhee GS, Chung HM, Chee KM, Kim GJ: Cytotoxicity of 5-fluorouracil: Effect on endothelial differentiation via cell cycle inhibition in mouse embryonic stem cells. Toxicol In Vitro 2009;23:719-727.

26 Liou KT, Shen YC, Chen CF, Tsao CM, Tsai SK: The anti-inflammatory effect of honokiol on neutrophils: mechanisms in the inhibition of reactive oxygen species production. Eur J Pharmacol 2003;475:19-27. 


\section{Cellular Physiology $\quad$ Cell Physiol Biochem 2012;30:758-770

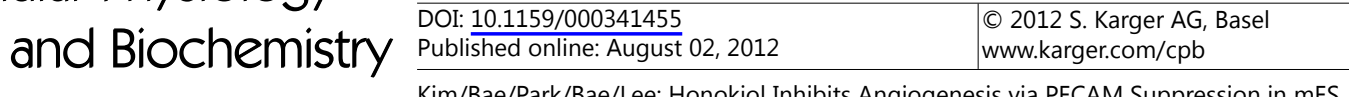

-27 Park EJ, Zhao YZ, Na M, Bae K, Kim YH, Lee BH, Sohn DH: Protective effects of honokiol and magnolol on tertiary butyl hydroperoxide- or D-galactosamine-induced toxicity in rat primary hepatocytes. Planta Med 2003;69:33-37.

28 Hu H, Zhang XX, Wang YY, Chen SZ: Honokiol inhibits arterial thrombosis through endothelial cell protection and stimulation of prostacyclin. Acta Pharmacol Sin 2005;26:1063-1068.

29 Matsui N, Takahashi K, Takeichi M, Kuroshita T, Noguchi K, Yamazaki K: Magnolol and honokiol prevent learning and memory impairment and cholinergic deficit in SAMP8 mice. Brain Res 2009;1305:108-117.

-30 Xu Q, Yi LT, Pan Y, Wang X, Li YC, Li JM: Antidepressant-like effects of themixture of honokiol andmagnolol fromthe barks of Magnolia officinalis in stressed rodents. Prog Neuropsychopharmacol Biol Psychiatry 2008;32:715-725.

-31 Munroe ME, Arbiser JL, Bishop GA: Honokiol, a natural plant product, inhibits inflammatory signals and alleviates inflammatory arthritis. J Immunol 2007;179:753-763.

32 Kuo DH, Lai YS, Lo CY, Cheng AC, Wu H, Pan MH: Inhibitory effect of magnolol on TPA-induced skin inflammation and tumor promotion in mice. J Agric Food Chem 2010;58:5777-5783.

-33 Nagase H, Ikeda K, Sakai Y: Inhibitory effect of magnolol and honokiol from Magnolia obovata on human fibrosarcoma HT-1080. invasiveness in vitro. Planta Med 2001;67:705-708.

-34 Ahn KS, Sethi G, Shishodia S, Sung B, Arbiser JL, Aggarwal BB: Honokiol potentiates apoptosis, suppresses osteoclastogenesis, and inhibits invasion through modulation of nuclear factor-kappaB activation pathway. Mol Cancer Res 2006;4:621-633.

35 Hibasami H, Achiwa Y, Katsuzaki H, Imai K, Yoshioka K, Nakanishi K, Ishii Y, Hasegawa M, Komiya T: Honokiol induces apoptosis in human lymphoid leukemia Molt 4B cells. Int J Mol Med 1998;2:671-673.

-36 Wang T, Chen F, Chen Z, Wu YF, Xu XL, Zheng S, Hu X: Honokiol induces apoptosis through p53-independent pathway in human colorectal cell line RKO. World J Gastroenterol 2004;10:2205-2208.

-37 Lee DH, Szczepanski MJ, Lee YJ: Magnolol induces apoptosis via inhibiting the EGFR/PI3K/Akt signaling pathway in human prostate cancer cells. J Cell Biochem 2009;106:1113-1122.

-38 Heuer J, Bremer S, Pohl I, Spielmann H: Development of an in vitro embryotoxicity test using murine embryonic stem cell cultures. Toxicol In Vitro 1993;7:551-556.

-39 Scholz G, Pohl I, Genschow E, Klemm M, Spielmann H: Embryotoxicity screening using embryonic stem cells in vitro: correlation to in vivo teratogenicity. Cells Tissues Organs 1999;165:203-211.

40 Alessi DR, Cuenda A, Cohen P, Dudley DT, Saltiel AR: PD 098059 is a specific inhibitor of the activation of mitogen-activated protein kinase in vitro and in vivo. J Biol Chem 1995;270:27489-27494.

41 Vlahos CJ, Matter WF, Hui KY, Brown RF: A specific inhibitor of phosphatidylinositol 3-kinase, 2-(4morpholinyl)-8-phenyl-4H-1-benzopyran-4-one (LY294002). J Biol Chem 1994;269:5241-5248.

42 Yang SE, Hsieh MT, Tsai TH, Hsu SL: Down-modulation of Bcl-XL, release of cytochrome c and sequential activation of caspases during honokiol-induced apoptosis in human squamous lung cancer CH27 cells. Biochem Pharmacol 2002;63:1641-1651.

43 Hu J, Chen L, Liu L, Chen X, Chen P, Yang G, Hou W, Tang M, Zhang F, Wang X, Zhao X, Wei Y: Liposomal honokiol, a potent anti-angiogenesis agent, in combination with radiotherapy produces a synergistic antitumor efficacy without increasing toxicity. Exp Mol Med 2008;40:617-628.

44 Yue W, Pi QM, Zhang WJ, Zhou GD, Cui L, Liu W, Cao Y: Platelet endothelial cell adhesion molecule-1, stagespecific embryonic antigen-1, and Flk-1 mark distinct populations of mouse embryonic stem cells during differentiation toward hematopoietic/endothelial cells. Stem Cells Dev 2010;19:1937-1948.

45 Cho DH, Choi YJ, Ahn JS, Ryou J, Kim JY, Chung J, Jo I: Troglitazone acutely inhibits protein synthesis in endothelial cells via a novel mechanism involving protein phosphatase 2A-dependent p70 S6 kinase inhibition. Am J Physiol Cell Physiol 2006;291:C317-C326.

-46 He L, Wu Y, Lin L, Wang J, Wu Y, Chen Y, Yi Z, Liu M, Pang X: Hispidulin, a small flavonoid molecule, suppresses the angiogenesis and growth of human pancreatic cancer by targeting vascular endothelial growth factor receptor 2-mediated PI3K/Akt/mTOR signaling pathway. Cancer Sci 2011;102:219-225.

-47 Dong Y, Lu B, Zhang X, Zhang J, Lai L, Li D, Wu Y, Song Y, Luo J, Pang X, Yi Z, Liu M: Cucurbitacin E, a tetracyclic triterpenes compound from Chinese medicine, inhibits tumor angiogenesis through VEGFR2mediated Jak2-STAT3 signaling pathway. Carcinogenesis 2010;31:2097-2104.

48 Strömblad S, Becker JC, Yebra M, Brooks PC, Cheresh DA: Suppression of p53 activity and p21WAF1/CIP1 expression by vascular cell integrin alphaVbeta3 during angiogenesis. J Clin Invest 1996;9:426-433. 